\title{
Women's psychosocial outcomes following an emergency caesarean section: A systematic literature review
}

\author{
Madeleine Benton $^{1 *} \mathbb{D}$, Amy Salter ${ }^{2}$, Nicole Tape ${ }^{1}$, Chris Wilkinson ${ }^{3}$ and Deborah Turnbull ${ }^{1}$
}

\begin{abstract}
Background: Given the sudden and unexpected nature of an emergency caesarean section (EmCS) coupled with an increased risk of psychological distress, it is particularly important to understand the psychosocial outcomes for women. The aim of this systematic literature review was to identify, collate and examine the evidence surrounding women's psychosocial outcomes of EmCS worldwide.
\end{abstract}

Methods: The electronic databases of EMBASE, PubMed, Scopus, and PsycINFO were searched between November 2017 and March 2018. To ensure articles were reflective of original and recently published research, the search criteria included peer-reviewed research articles published within the last 20 years (1998 to 2018). All study designs were included if they incorporated an examination of women's psychosocial outcomes after EmCS. Due to inherent heterogeneity of study data, extraction and synthesis of both qualitative and quantitative data pertaining to key psychosocial outcomes were organised into coherent themes and analysis was attempted.

Results: In total 17,189 articles were identified. Of these, 208 full text articles were assessed for eligibility. One hundred forty-nine articles were further excluded, resulting in the inclusion of 66 articles in the current systematic literature review. While meta-analyses were not possible due to the nature of the heterogeneity, key psychosocial outcomes identified that were negatively impacted by EmCS included post-traumatic stress, health-related quality of life, experiences, infant-feeding, satisfaction, and self-esteem. Post-traumatic stress was one of the most commonly examined psychosocial outcomes, with a strong consensus that EmCS contributes to both symptoms and diagnosis.

Conclusions: EmCS was found to negatively impact several psychosocial outcomes for women in particular post-traumatic stress. While investment in technologies and clinical practice to minimise the number of EmCSs is crucial, further investigations are needed to develop effective strategies to prepare and support women who experience this type of birth.

Keywords: Systematic literature review, Childbirth, Emergency caesarean section, Psychosocial outcomes, Maternal health, Postpartum

\footnotetext{
* Correspondence: madeleine.benton@adelaide.edu.au

${ }^{1}$ School of Psychology, University of Adelaide, Adelaide, South Australia,

Australia

Full list of author information is available at the end of the article
}

(c) The Author(s). 2019 Open Access This article is distributed under the terms of the Creative Commons Attribution 4.0 International License (http://creativecommons.org/licenses/by/4.0/), which permits unrestricted use, distribution, and reproduction in any medium, provided you give appropriate credit to the original author(s) and the source, provide a link to the Creative Commons license, and indicate if changes were made. The Creative Commons Public Domain Dedication waiver (http://creativecommons.org/publicdomain/zero/1.0/) applies to the data made available in this article, unless otherwise stated. 


\section{Introduction}

There has been a dramatic increase in caesarean section (CS) rates around the world over the past three decades, particularly in middle and high income countries [1]. At a population level, the World Health Organization has concluded that CS rates higher than $10 \%$ are not associated with reductions in maternal and newborn mortality rates [2]. Despite this, recent data has reported rates of $40.5 \%$ in Latin America and the Caribbean, 32.3\% in Northern America, 31.1\% in Oceania, 25\% in Europe, 19.2\% in Asia and $7.3 \%$ in Africa [3]. Globally, CS rates have almost doubled between 2000 and 2015, from 12 to $21 \%$ [4].

CSs are broadly classified depending on whether they are an elective or emergency procedure. An elective CS is defined as a planned, non-emergency delivery which occurs before initiation of labour [5]. In contrast, emergency caesarean section (EmCS) is defined as an unplanned CS delivery performed before or after onset of labour, which is typically urgent and is most often required due to fetal, maternal or placental conditions (eg. fetal distress, eclampsia, placental/cord accidents, uterine rupture, failed instrumental birth etc) $[5,6]$.

While CS has an important place in potentially protecting both mother and baby from harm, it is associated with short and long term physical and psychological risks which can extend many years beyond the current delivery and effect the health of the woman, her child, and future pregnancies [7]. In a review of research on the outcomes of CS, Lobel [8] noted that the procedure is uniquely challenging as it combines surgery and birth, events that elicit very diverse emotional responses. The circumstances surrounding an EmCS add an additional layer of complexity to this experience which has thereby prompted researchers to explore the psychosocial impact of this type of birth. The nature of the event accompanied by a series of subsequent rapid psychological adjustments may be distressing, anxiety-provoking and emotionally unsettling for women $[9,10]$.

The primary outcome of obstetric care, is of course, to ensure both mother and infant remain physically healthy however, psychosocial aspects and outcomes of maternity care and obstetrics are no less important $[11,12]$. Psychosocial outcomes identified and examined in the literature as potentially related to CS include: mental health problems such as, postpartum depression, posttraumatic stress and anxiety; decreased maternal satisfaction with childbirth; the mother infant relationship; parents' sexual functioning; and health behaviours such as infant feeding.

\section{The current study}

Given the nature of EmCS and the increased risk of psychological distress for women, it is imperative to gain insight into the diverse psychosocial outcomes for women experiencing this type of birth. Knowledge and awareness surrounding the impact of EmCS on women's psychosocial outcomes is likely to enhance the overall quality of maternity care. The aim of the current systematic literature review is to identify, collate, and examine the evidence surrounding women's psychosocial outcomes of EmCS.

\section{Method}

A systematic literature review constituting a rigorous method of research for summarising evidence from multiple studies on a specific topic was undertaken $[13,14]$. The present study was conducted in accordance with the Preferred Reporting Items for Systematic Reviews and Meta-analyses (PRISMA) recommendations [15]. An a priori designed study protocol guided the literature search, study selection and data synthesis, with quantitative meta-analysis attempted when possible. This systematic review was registered in the international prospective register of systematic reviews (PROSPERO) database: CRD42018087677.

\section{Search strategy}

The search strategy was designed and developed following consultation with a health and medical sciences university librarian in order to ensure a comprehensive search and increase the robustness of the study [16]. The medical and psychological electronic databases of EMBASE, PubMed, Scopus, and PsycINFO were searched between November 2017 and March 2018. When conducting searches, keywords were combined representing the two primary concepts; psychosocial outcomes and EmCS. In this systematic literature review, psychosocial outcomes were considered to be variables that encompass social and psychological aspects of an individual's life [17]. The Boolean operators 'OR' and 'AND' were utilised to facilitate maximum inclusion of relevant articles [18]. Detailed search algorithms and indexing language used for each database are outlined in the Additional File 1.

To ensure that included articles were reflective of original and recently published research, limits were applied within the literature search to incorporate inclusion criteria such as: research articles, publication within the last 20 years (1998 to 2018), and peer-reviewed articles [19]. Further, the search was limited to English language publications due to unavailability of funding for language translation. Grey literature or trial registries were not persued for practical purposes.

\section{Eligibility criteria}

Inclusion and exclusion criteria (based on the PICOS [population, intervention, comparison, outcome, study design] framework) were established in advance and 
documented in the review protocol to identify all pertinent studies.

- Population: Women who have delivered via EmCS

- Intervention: EmCS

- Comparison: Any mode of delivery (MoD) where reported, otherwise no comparison

- Outcomes: Psychosocial variables (i.e. postnatal depression, anxiety, post-traumatic stress, infant feeding, sexual functioning, satisfaction, views and experiences)

- Study Design: Quantitative (excluding case studies), qualitative or mixed methods

\section{Study selection}

Potential papers were screened initially by title and abstract by two reviewers who reviewed half of papers each (MB and NT) and full texts were retrieved for those citations considered potentially relevant for inclusion. Both reviewers completed an initial subset of papers together in order to ensure consistency in their approach. Reference lists of retrieved full text papers were examined to identify potentially relevant studies not captured by electronic searches [20]. Full texts of the remaining articles were independently appraised against the eligibility criteria for final inclusion by two reviewers (MB and NT). In case of disagreement in the selection process, a third reviewer was available for consultation.

\section{Data extraction}

Utilising a data extraction form designed by the authors, MB extracted descriptive data on study aims, study design, study location, sample size, data collection period, measures utilised, and included a text description summarising the psychosocial and EmCS related findings from each study. These data were cross-checked by NT. A data synthesis of the findings from each article was then performed, involving identification of prominent and recurrent themes in the literature and the synthesis of findings from studies under thematic headings. This approach has been described as flexible, allowing considerable latitude to systematic reviewers, and provides a means of integrating qualitative and quantitative evidence [20].

\section{Quality assessment}

In line with standard systematic literature review methodology a formal methodological quality appraisal of each included study was performed using the Mixed Methods Appraisal Tool (MMAT) version 11 [21]. This tool allows for the critical appraisal of quantitative, qualitative, and mixed methods studies and was developed to address some of the challenges of critical appraisal in systematic mixed studies reviews. The MMAT has been validated and used for quality assessment in similar mixed method systematic reviews [22]. The MMAT comprises 19 items for appraising the methodological quality of 5 different types of studies: qualitative studies (4 items), randomised controlled trials (4 items), non-randomized studies (4 items), quantitative descriptive studies ( 4 items), and mixed methods studies (4 items). Based on the number of criteria met for an individual study, the overall quality assessment rating (QAR) is presented using descriptors ${ }^{*}, \cdots, * * *$, and ${ }^{* * * * *}$, ranging from * (single criterion met) to ${ }^{* * * *}$ (all criteria met). Each study included in the quality assessment was evaluated by two independent reviewers (MB and NT). A third reviewer was available for consultation if disagreement occurred.

\section{Results}

\section{Study selection and characteristics}

A summary of the search process is illustrated in Fig. 1, as recommended by the PRISMA guidelines [15]. In total 17,189 articles were initially identified. For the initial screening, all search results were imported into citation management software Endnote $\times 7$ where 1068 duplicates were identified and removed, leaving 16,121 articles (Pubmed, $n=12,960$, EMBASE $n=829$, PsycINFO $n=56$, Scopus $n=2276$ ). Titles and abstracts were then assessed by two reviewers (MB, NT), with this process ending with the inclusion of 208 articles. Full texts were then retrieved for those citations considered potentially relevant and assessed for eligibility by the two reviewers (MB, NT). Of these 208 articles, 149 were excluded. The most common reason for exclusion was a lack of differentiation between type of CS when reporting study results (see Fig. 1). Reference lists of included studies were hand searched by the first author and a further 7 articles were subsequently included. A total of 66 relevant articles $[5,9,23-86]$ were thus included in the current systematic literature review.

\section{Description of included studies}

Characteristics of the 66 included studies are presented in Table 1. Studies were conducted in 22 different countries with the majority conducted in Sweden $(n=12)$, followed by the UK $(n=10)$, and then Nigeria $(n=5)$. Most studies were quantitative in nature $(n=51)$, followed by qualitative $(n=14)$ and just one study with mixed methods. Cross sectional $(n=19)$ and prospective designs $(n=31)$ were most prevalent.

\section{Quality assessment}

Mixed Methods Appraisal Tool quality assessment ratings (MMAT QARs) are included in Table 1. Among the 51 quantitative non-randomised studies, 14 met all five criteria, 31 met four criteria, 4 met three criteria and 


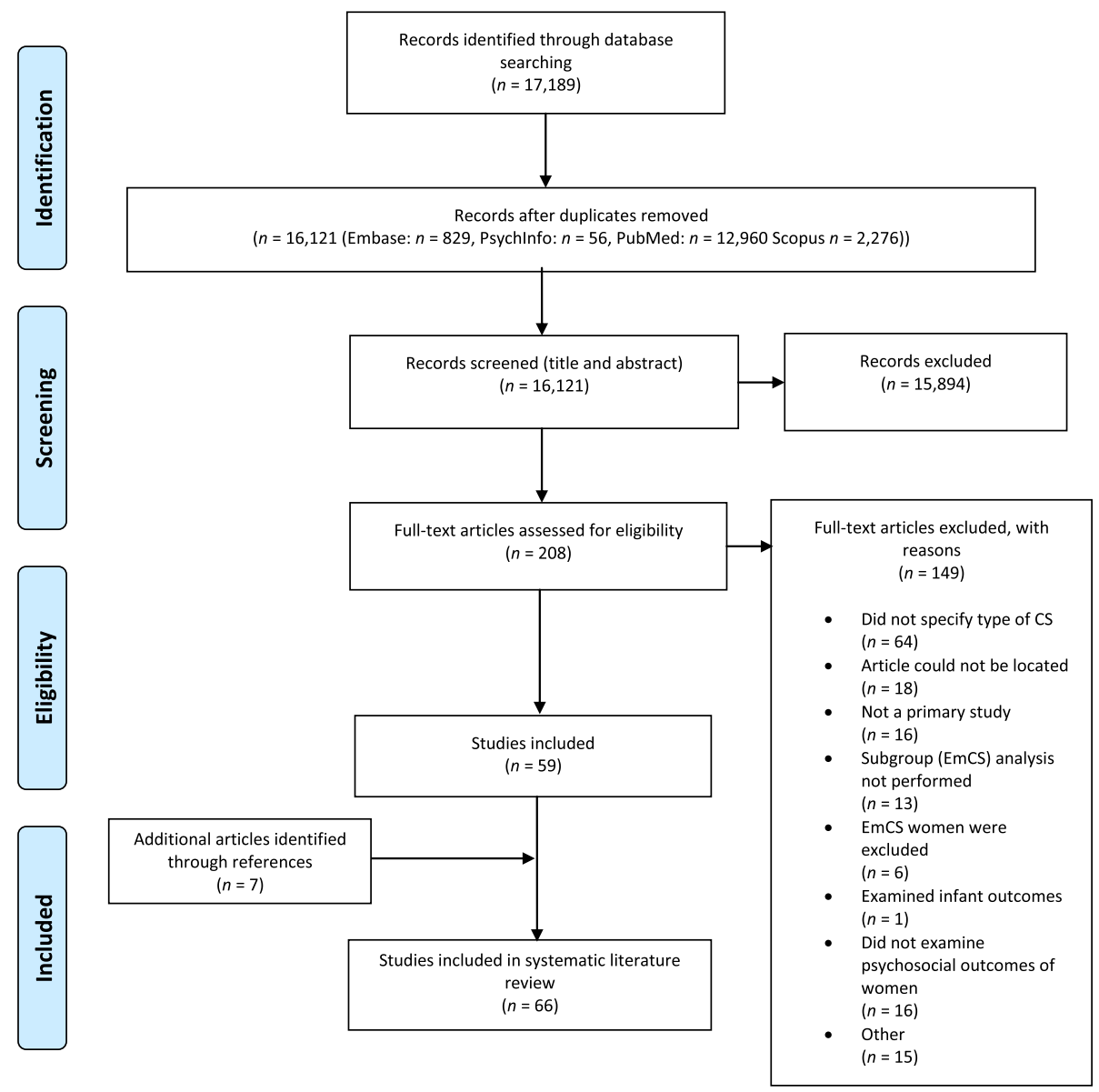

Fig. 1 Search and Selection Flow Diagram

2 met two criteria. Of the 14 qualitative studies, 12 met all five criteria. The one study with mixed methods met four of the five criteria. The main reason several quantitative studies did not meet all criteria was a lack of reporting for the complete set of outcomes (without adequate justification), response rate or follow-up rate.

\section{Data extraction and synthesis}

Key psychosocial outcomes were examined in the final 66 studies. Data synthesis was employed to extract and synthesise data pertaining to key psychosocial outcomes from each study into coherent themes. Psychosocial outcomes potentially associated with EmCS included postpartum depression, post-traumatic stress, health related quality of life, mother infant bonding, infant feeding, sexual function, experiences, satisfaction, selfesteem, distress, and fear. Due to an excess of methodological heterogeneity between studies (even for subsets of studies with some common features), a metaanalysis was deemed inappropriate. Table 2 summarizes evidence of associations for identified psychosocial outcomes and EmCS.

\section{Key outcomes}

Postpartum depression

Twelve studies examined depression as an outcome of EmCS [33, 36, 38, 43, 45, 51, 60, 62, 71, 80, 85, 87]. These studies used varying measures, with the majority $(n=8)$ utilising the Edinburgh Postnatal Depression Scale (EPDS), three using Beck's Depression Inventory (BDI) and one study not specifying the measure used. Studies identified reported mixed findings in terms of postpartum depression (PPD) and the experience of EmCS. The majority of studies found no significant association between having an EmCS and PPD relative to other MoDs [33, 38, 43, 45, 62, 80, 85]. For example, a prospective cohort study $(n=10,934)$ from the UK found no significant evidence of increased risk of PPD between different MoDs including EmCS [62]. In contrast, a much smaller prospective cohort study reported EmCS was a predictor of PPD [51]. Additionally, a recent cross-sectional study conducted in Iran [71] reported that the prevalence of PPD was $33.4 \%$, of which the highest proportion consisted of women who had experienced EmCS at 41.3\%. Furthermore, a recent large longitudinal study found that compared with spontaneous VD, women who delivered 


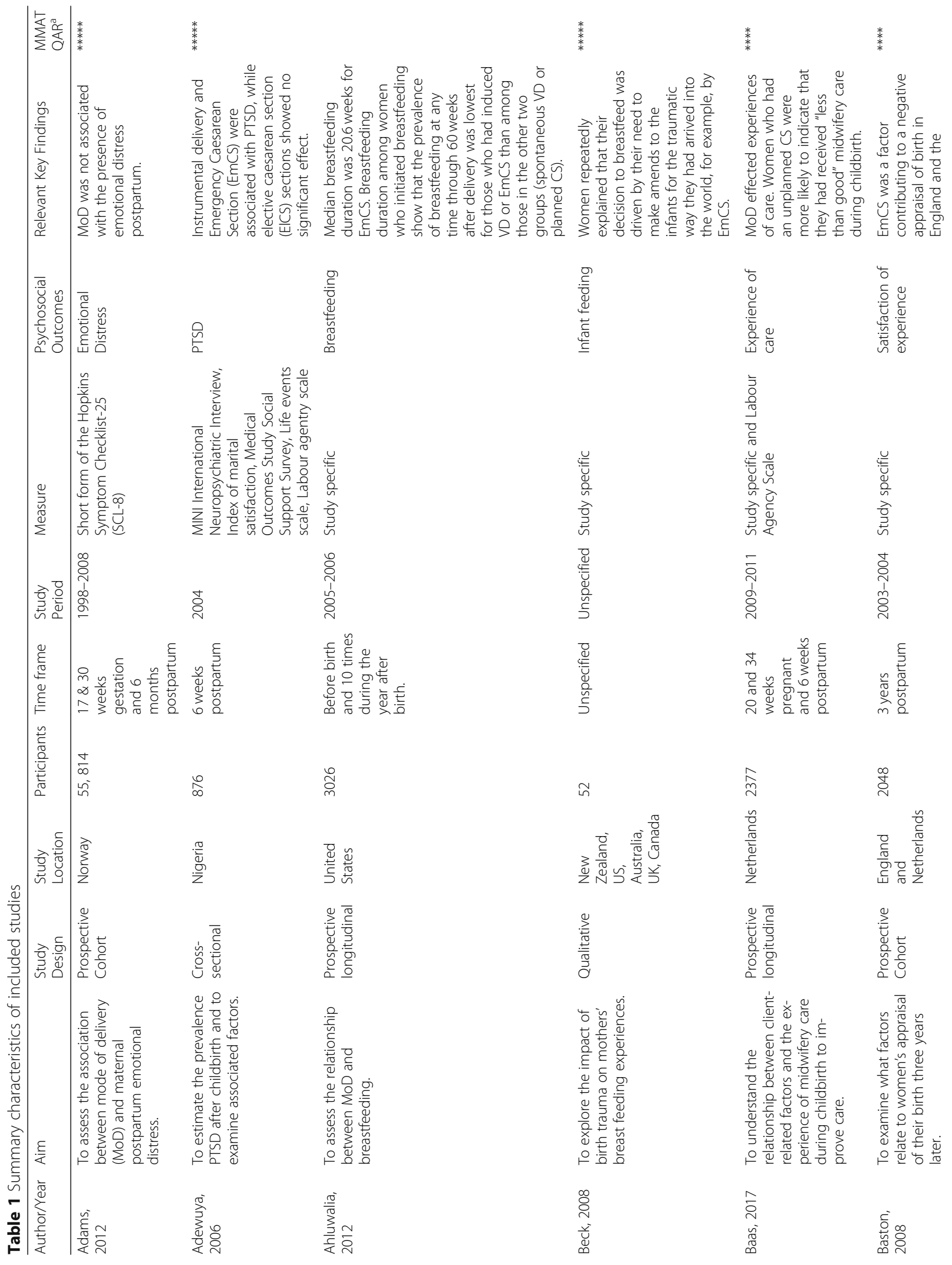




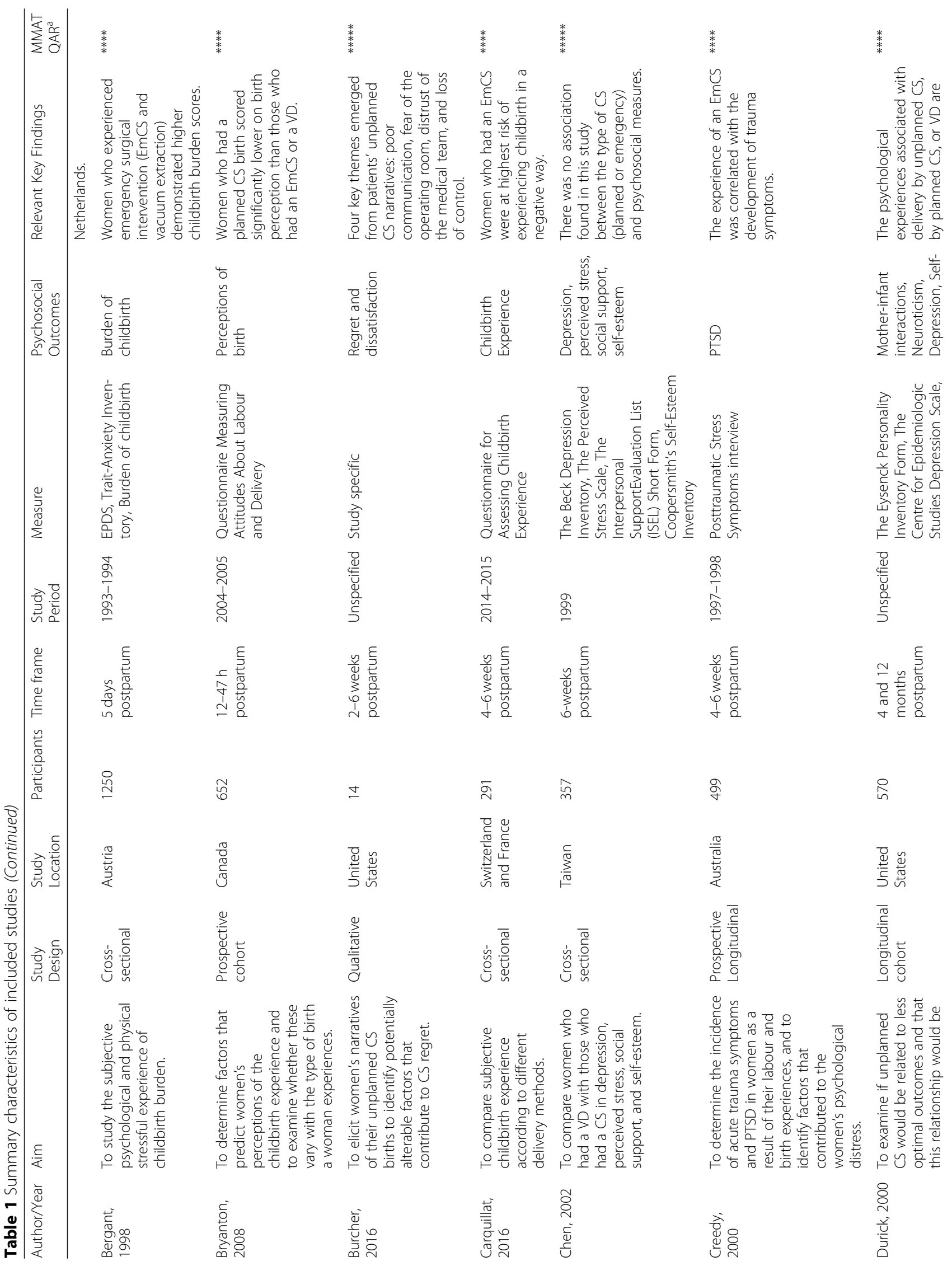




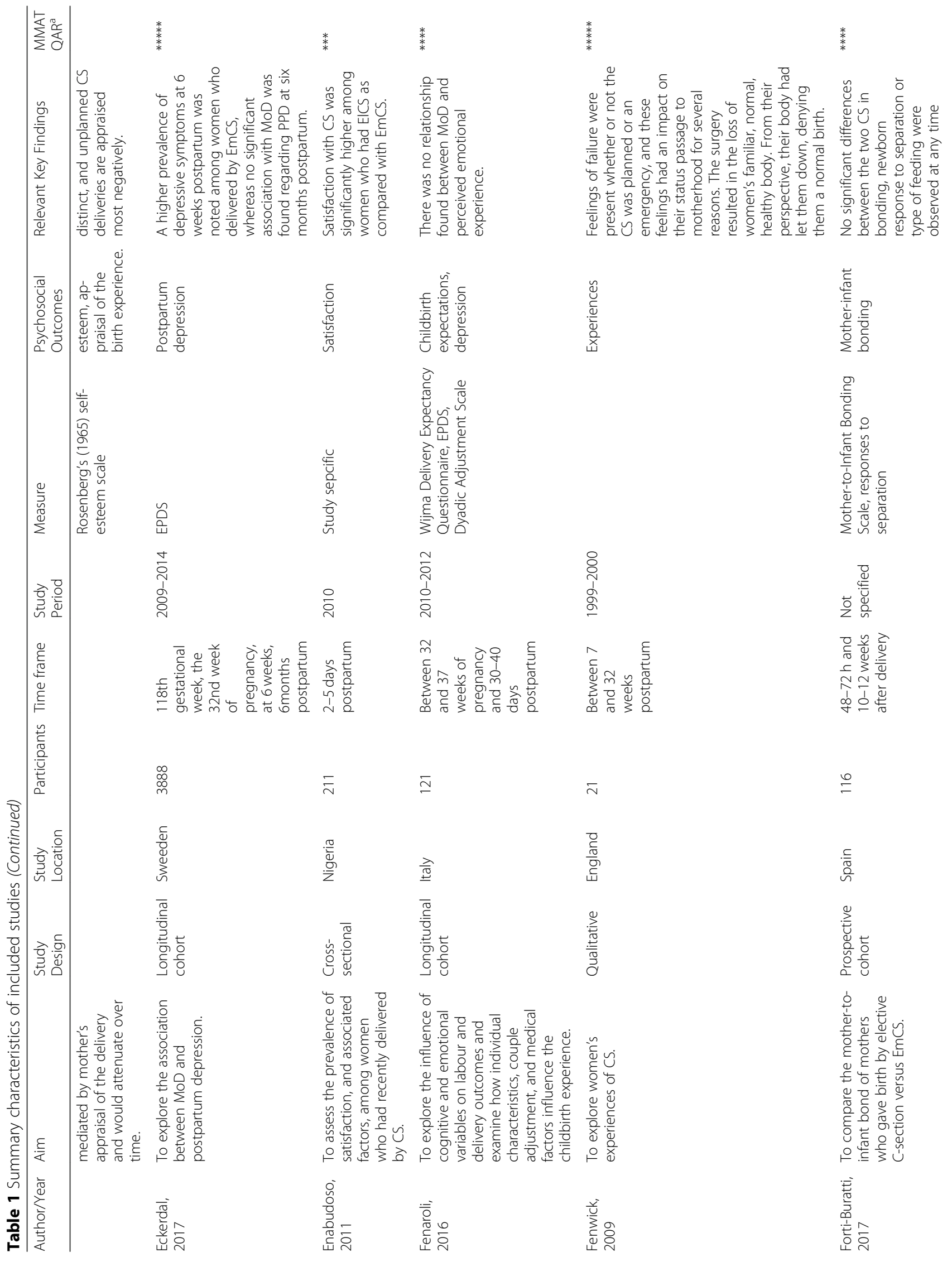




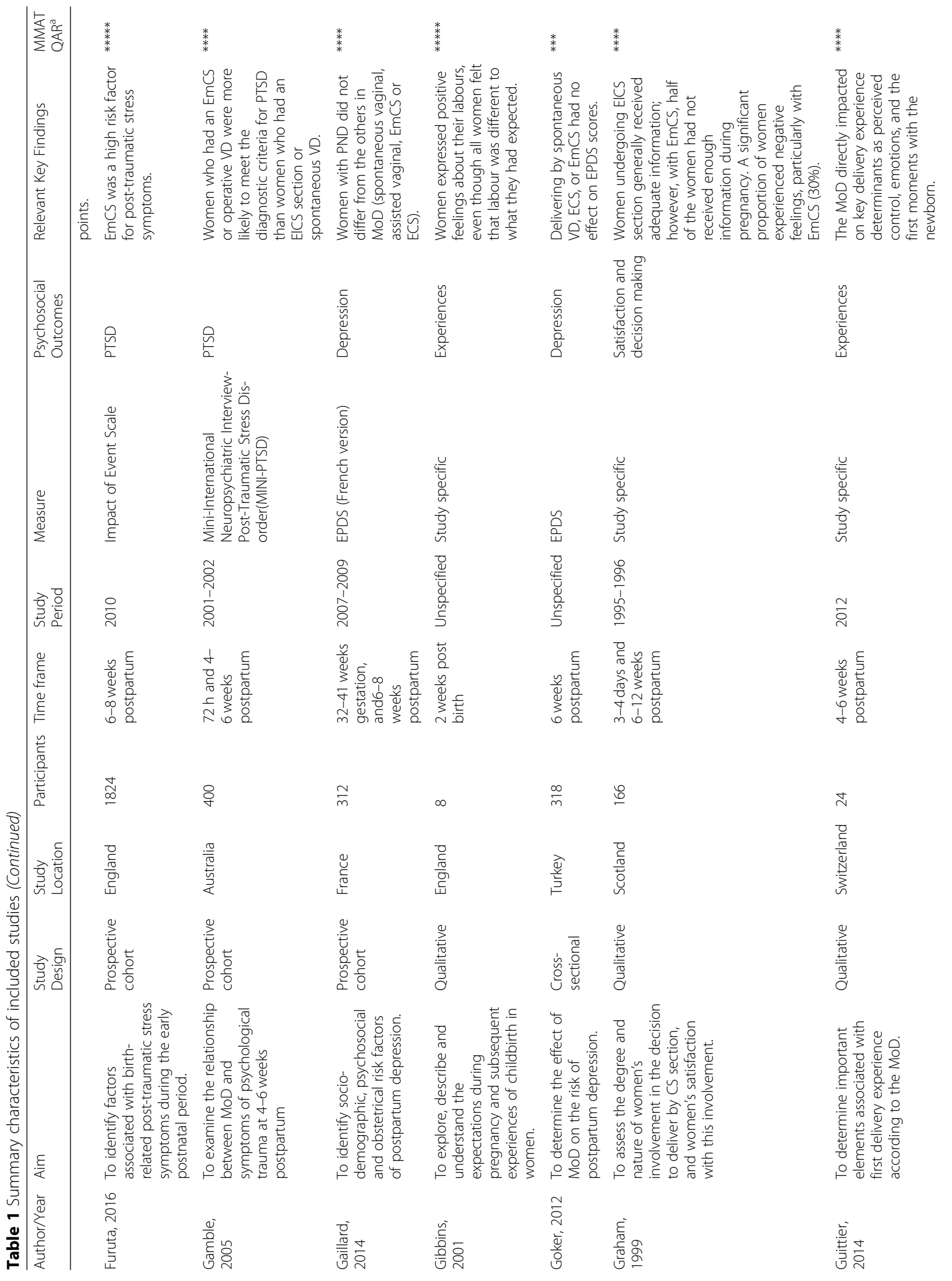




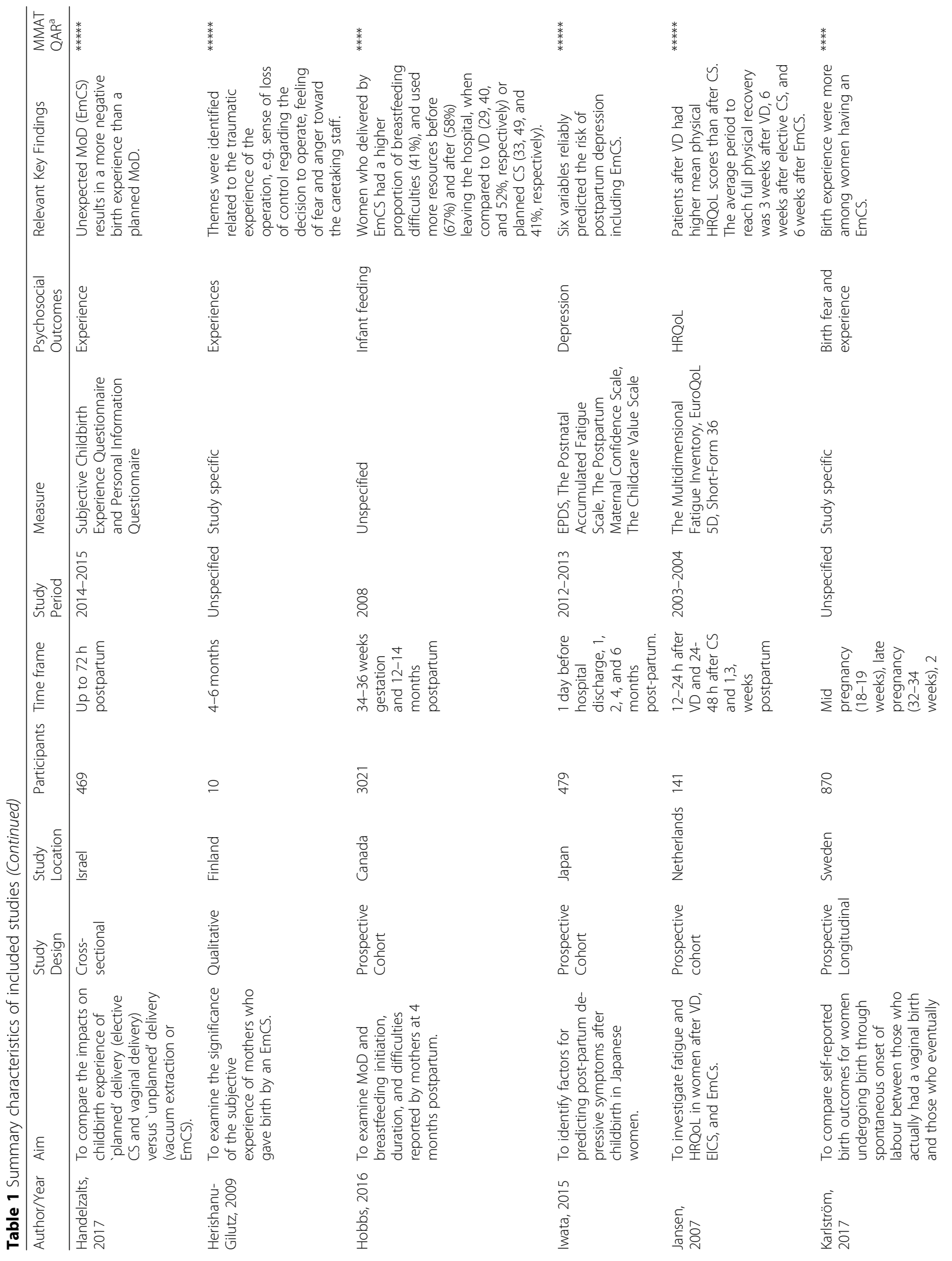




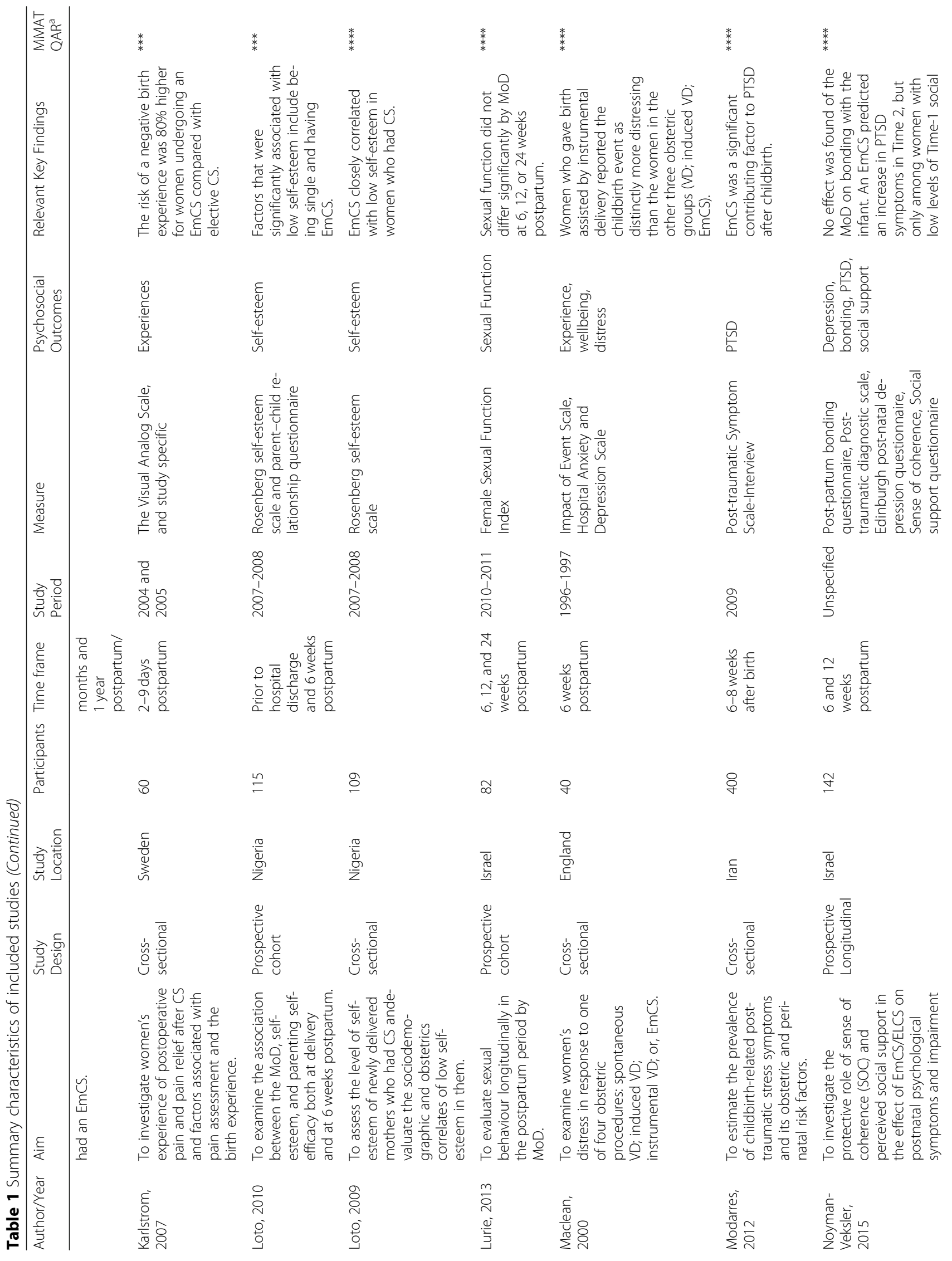




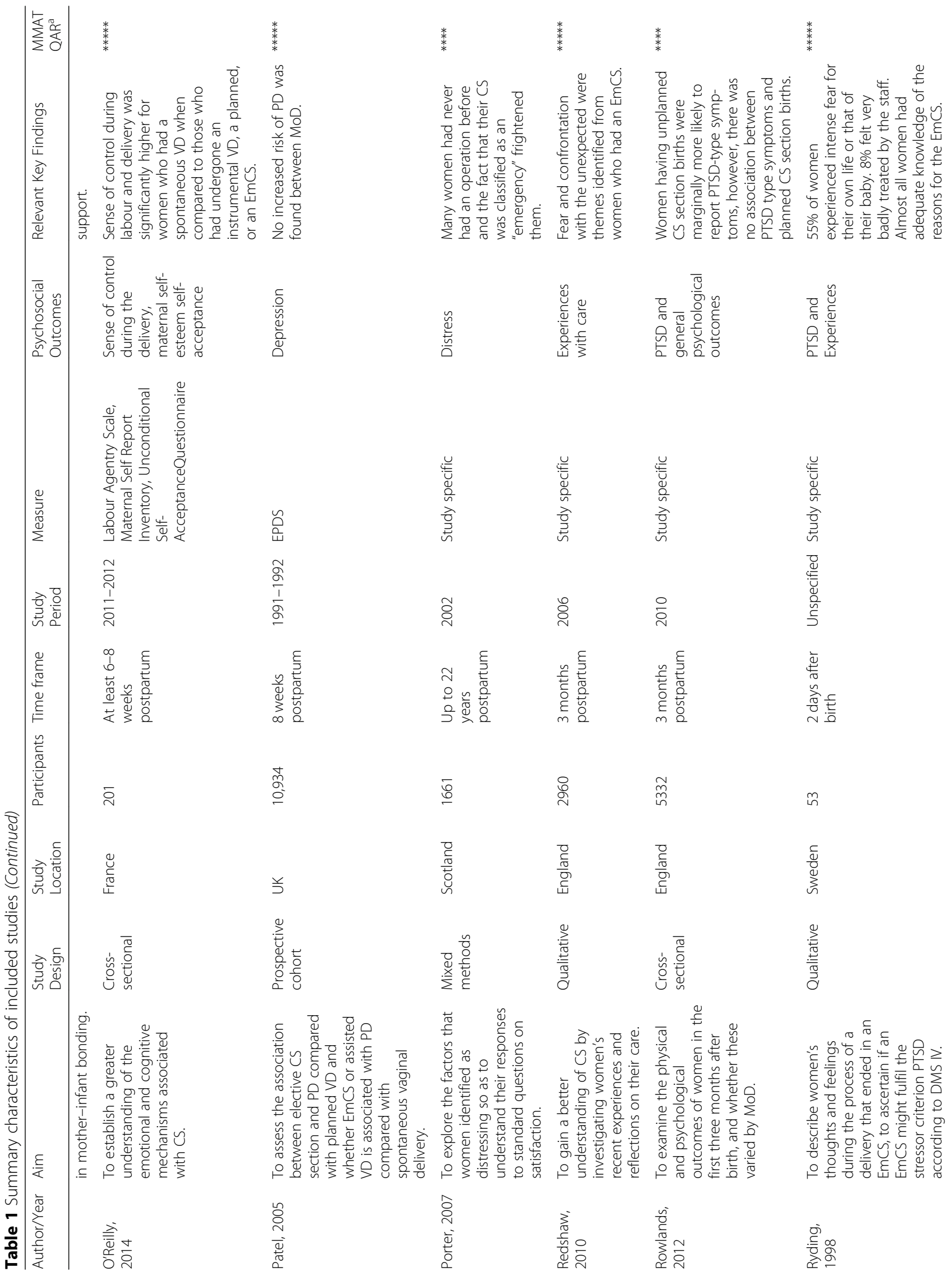




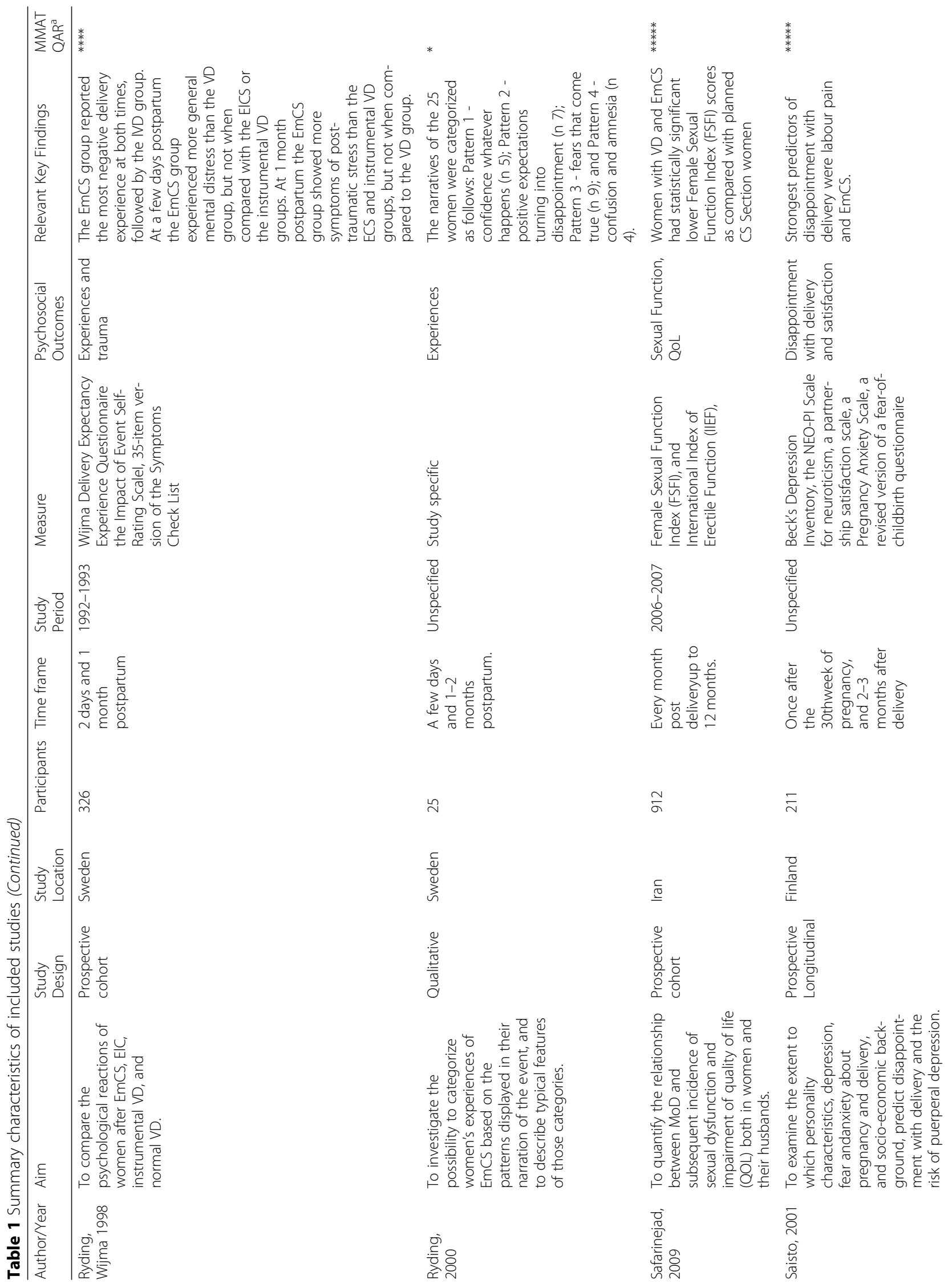




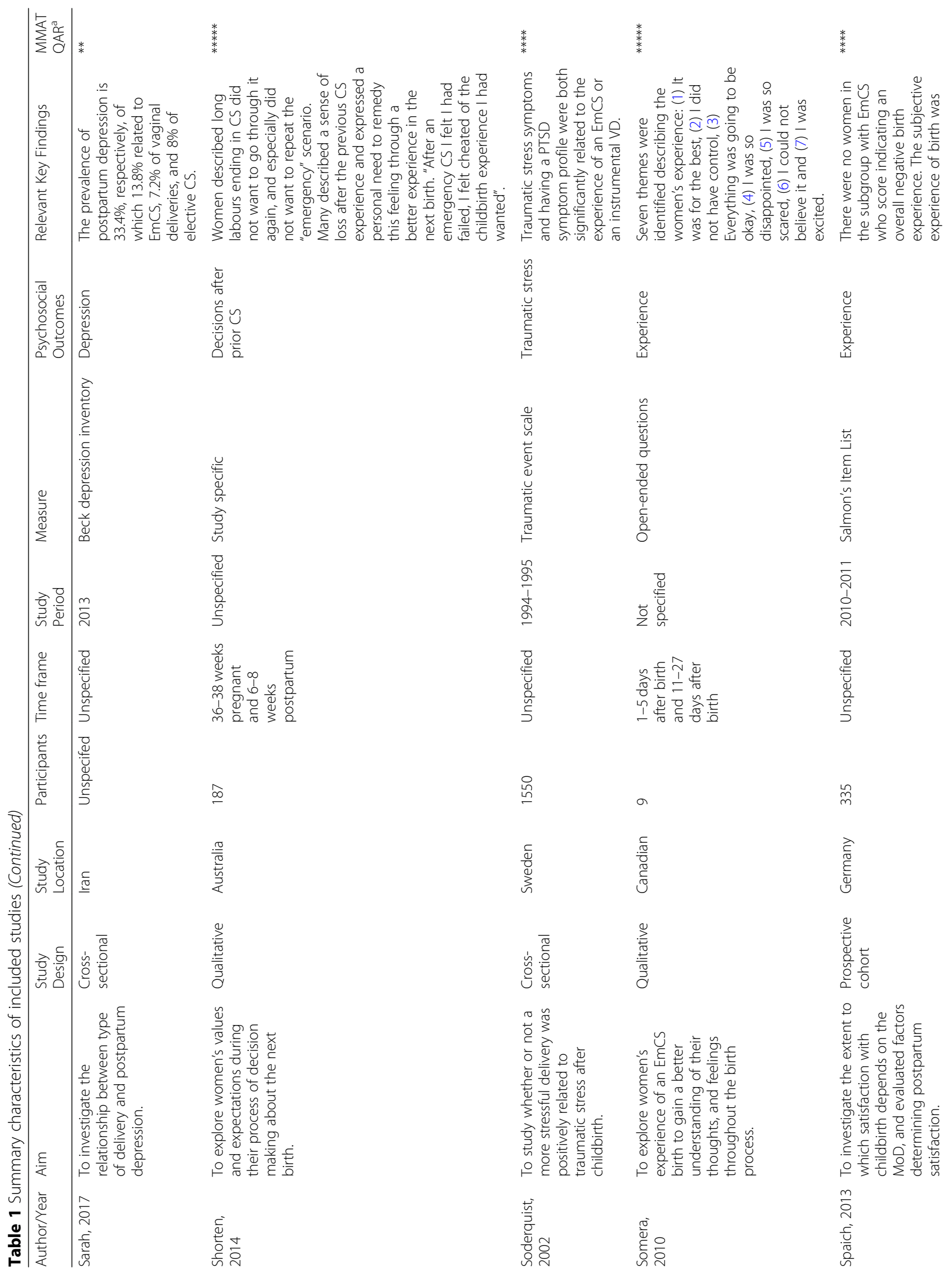




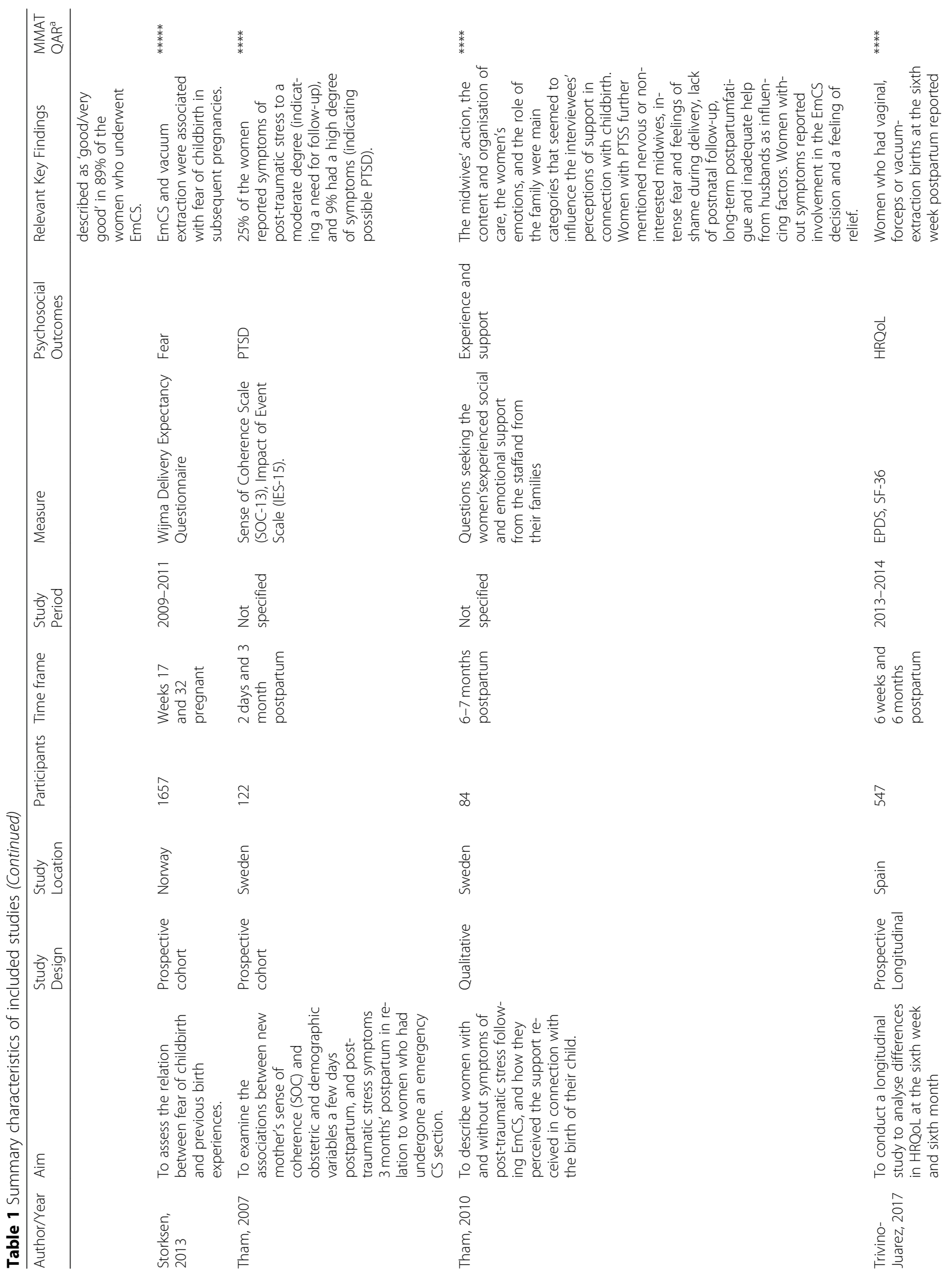




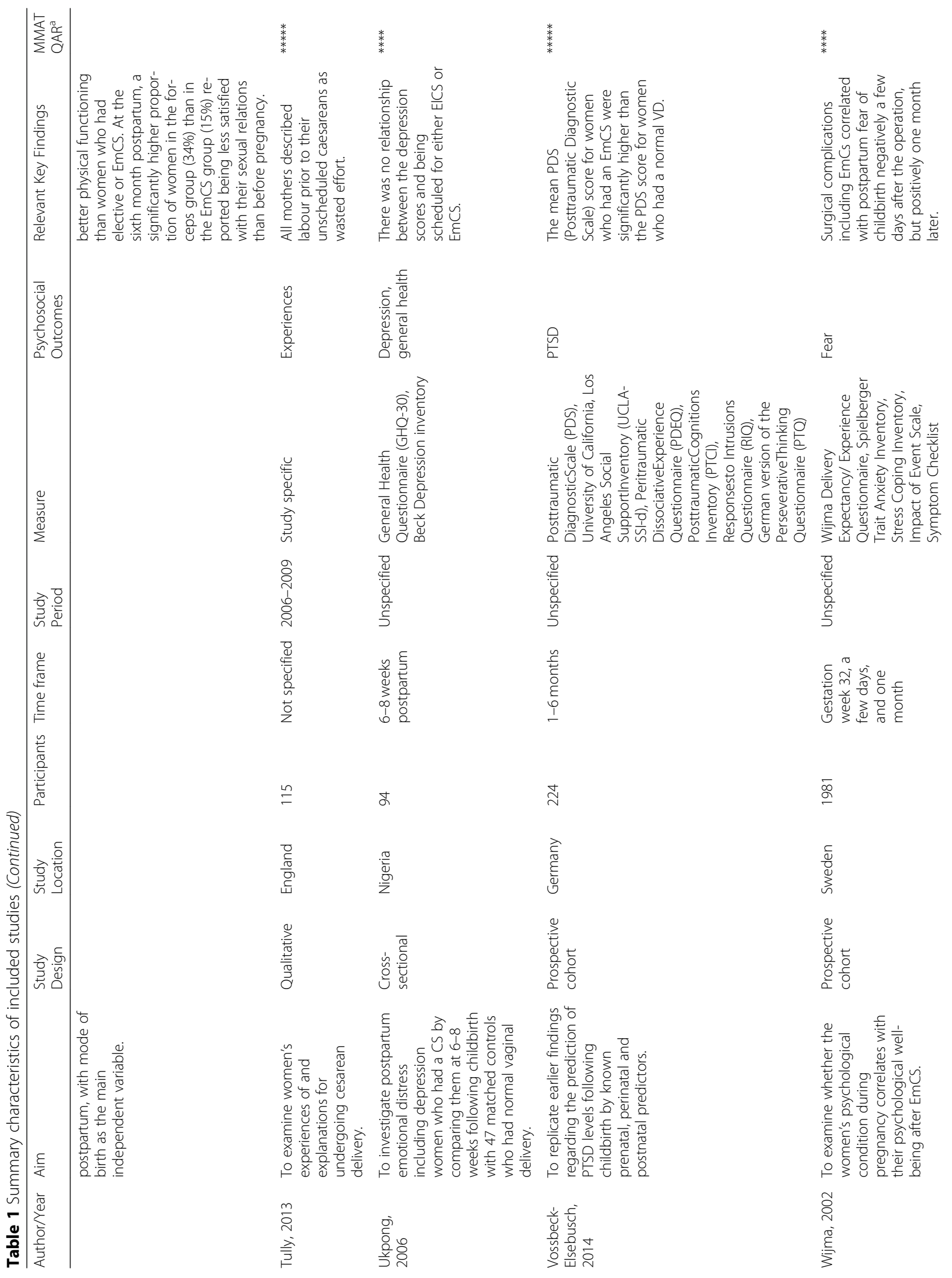




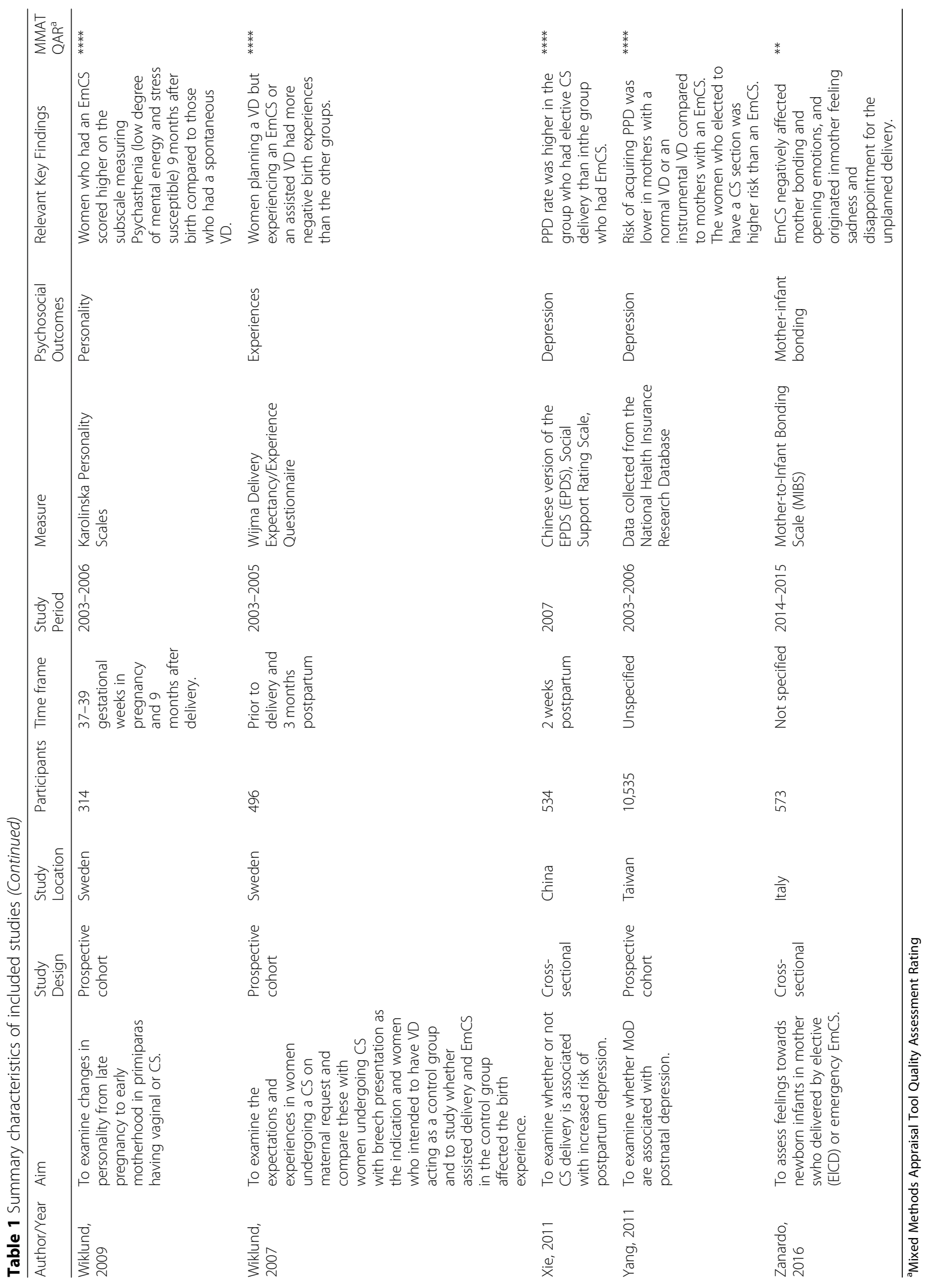


Table 2 Associations of identified psychosocial outcomes and EmCS

\begin{tabular}{lllll}
\hline $\begin{array}{l}\text { Key } \\
\text { psychosocial } \\
\text { outcomes }\end{array}$ & $\begin{array}{l}\text { Number } \\
\text { of } \\
\text { studies }\end{array}$ & $\begin{array}{l}\text { Association between } \\
\text { EmCS and psychosocial } \\
\text { outcomes }\end{array}$ & $\begin{array}{l}\text { Inconclusive associations } \\
\text { between EmCS and } \\
\text { psychosocial outcomes }\end{array}$ & Qualitative summary \\
\hline $\begin{array}{l}\text { Postpartum } \\
\text { depression }\end{array}$ & 12 & & + & $\begin{array}{l}\text { Studies reported inconsistent findings. The majority of studies } \\
\text { reported no significant association }(n=7) \text { between EmCS and PPD } \\
\text { (PPD) }\end{array}$ \\
& & & $\begin{array}{l}\text { whereas the remaining studies reported a relationship between } \\
\text { EmCS and increased symptoms of PPD }(n=5) .\end{array}$
\end{tabular}

$\begin{aligned} & \text { Post-traumatic } \\ & \text { stress disorder }\end{aligned}$
$\begin{aligned} & \text { (PTSD) } \\ & \text { Health related }\end{aligned}$
$\begin{aligned} & \text { quality of life } \\ & \text { Mother infant }\end{aligned}$
bonding

Infant feeding $3 \quad-$

Sexual function 3

Experiences $21 \quad+/-$

\begin{tabular}{|c|c|c|}
\hline Satisfaction & 4 & - \\
\hline Self-esteem & 3 & - \\
\hline Distress & 3 & \\
\hline Fear & 2 & \\
\hline Other & & \\
\hline $\begin{array}{l}\text { Childbirth } \\
\text { Burden }\end{array}$ & 1 & + \\
\hline $\begin{array}{l}\text { Feelings of } \\
\text { control }\end{array}$ & 1 & - \\
\hline
\end{tabular}

All studies $(n=11)$ reported consistent findings that EmCS was a contributing factor to increasing post-traumatic stress symptoms and PTSD after childbirth.

Consistent findings were found across studies $(n=2)$ that women who had an EmCS had poorer physical functioning compared to other MoDs.

Studies reported inconsistent findings. In $n=1$ study EmCS appeared to have a negative association with mothers bonding and opening emotions with their baby. In contrast, no significant affect was found in terms of MoD on mother-infant bonding in the remaining studies $(n=2)$.

Consistent findings were found across studies in that EmCS impacted negatively in varying ways on infant feeding $(n=3)$. Women who have an EmCS were more likely to have had an unsuccessful first breastfeeding attempt, were less likely to breastfed their baby within the first $24 \mathrm{~h}$ and upon leaving the hospital, and to breastfeed for a shorter duration of time compared to other MoDs.

Studies were inconsistent in their findings $(n=3)$ in terms of satisfaction with sexual relations after birth and sexual function postpartum.

In terms of quantitative research $(n=9)$, the majority of studies found that EmCS was more likely to result in a negative birth experience $(n=6), n=1$ study reported MoD had no influence on mother experiences and $n=2$ studies reported that EmCS was related to positive experiences in comparison to other MoDs. In terms of the qualitative studies $(n=12)$ women described a wide variety of emotions as salient aspects to their EmCS experience however, a number of dominating negative experiences were consistent across all studies

Consistent findings were reported across all studies $(n=4)$ with women who had an EmCS more likely to appraise their deliveries less favourably than those who delivered via other MoDs.

Consistent findings were reported across all studies $(n=3)$. Women who had an EmCS were more likely to report feelings of emotional vulnerability after delivery including feelings of failure, regret, and lower self-esteem.

Findings were inconsistent in terms of distress after EmCS. No significant association between MoD and distress were reported in a study $(n=1)$, another study reported other MoD causing more distress than EmCS $(n=1)$, the final study reported a relationship between EmCS and distress.

Inconsistent findings were reported. With $n=1$ study reporting EmCS was associated with increased fear of childbirth in subsequent pregnancies and $n=1$ study reporting a correlation with fear of childbirth a few days after the operation, however this decreased one month later.

Women who experienced emergency surgical intervention (i.e EmCS) were more likely to demonstrate higher childbirth burden scores than any other $\operatorname{MoD}(n=1)$.

Women who had a spontaneous VD reflected having a significantly higher sense of control during their labour and childbirth relative to with an instrumental VD, a planned CS, or an EmCS $(n=1)$.

+ indicates that some (or all) evidence supports a positive association 
by EmCS had significantly higher odds of PPD 6 weeks after delivery $(\mathrm{OR}=1.45)$ [36]. Additionally, a cohort study $(n=10,535)$ reported that the odds of PPD was significantly lower for women who had a normal VD $(\mathrm{OR}=0.67)$ or an instrumental VD $(\mathrm{OR}=0.56)$ compared to women who had EmCS [87]. However, women who had an elective CS had higher odds of PPD than women who had EmCS (OR = 1.48, $p=0.0168$ ) [87]. Heterogeneity in the tools, their use and findings can be seen in Table 3 and makes the comparison of these figures problematic.

\section{Traumatic stress}

Eleven included studies examined trauma as an outcome of an EmCS [24, 34, 41, 42, 59, 60, 65, 66, 73, 76, 81]. These studies were conducted across a diverse range of countries including Australia, Nigeria, UK, Iran, Israel, Sweden and Germany. Study designs included, six crosssectional, four prospective and one qualitative. All studies consistently reported that EmCS was a contributing factor for post-traumatic stress symptoms and Post Traumatic Stress Disorder (PTSD) after childbirth. Several of the studies stated that any unplanned interventions during childbirth including EmCS were predictors of PTSD [42, 88]. For example, a prospective cohort study $(n=1824)$ identified EmCS as a risk factor for post-traumatic stress symptoms [41]. Findings from a smaller cross-sectional study in Australia reported a greater than expected frequency of PTSD in women who had EmCS, specifically, 73\% reporting trauma symptoms
4-6 weeks postpartum [42]. Further, a qualitative research study conducted in Sweden concluded that experiences of women who delivered via EmCS were traumatic enough to fulfil the stressor criterion of PTSD in the DSM IV [66]. This study stated that 55\% of women interviewed a few days after an EmCS reported feelings of intense fear of death or injury to themselves or to their baby during the delivery process [66].

\section{Health related quality of life}

Two studies specifically examined Health Related Quality of Life (HRQoL) [52, 78]. One study utilised the Short-Form 36 (SF-36) to measure HRQoL [78] and the other utilised the SF-36 and the EuroQoL 5D [52]. Both studies reported consistent findings that women with an EmCS had poorer physical functioning, relative to other MoDs. A prospective study in the Netherlands reported that the average period to reach full physical recovery was 3 weeks after VD, 6 weeks after elective CS and EmCS [52]. Similarly, a larger more recent study reported that women who had a vaginal, forceps or vacuum-extraction delivery, had better physical functioning at 6 weeks postpartum relative to those with elective CS or EmCS [78]. In a cohort study in Sweden, women who had EmCS scored higher on the subscale measuring Psychasthenia (low degree of mental energy and stress susceptible) 9 months after birth relative to those with spontaneous VD [84].

Table 3 Heterogeneity across studies examining depression

\begin{tabular}{|c|c|c|c|c|c|c|c|}
\hline Study & Cut score & $\begin{array}{l}\text { Time } \\
\text { post } \\
\text { partum }\end{array}$ & $\begin{array}{l}\text { Sample } \\
\text { size }\end{array}$ & $\begin{array}{l}\text { Participants } \\
\text { with } \\
\text { depression }\end{array}$ & $\begin{array}{l}\text { EmCS } \\
\text { subgroup }\end{array}$ & $\begin{array}{l}\text { EmCS subgroup } \\
\text { with depression }\end{array}$ & $\begin{array}{l}\text { Evidence of association } \\
\text { between EmCS and PPD }\end{array}$ \\
\hline \multicolumn{8}{|c|}{ Edinburgh Postnatal Depression Scale } \\
\hline $\begin{array}{l}\text { Eckerdal, } \\
2017\end{array}$ & EDPS $>12$ & 6 weeks & 3888 & $505(13 \%)$ & 346 & $50(16.7 \%)$ & No \\
\hline $\begin{array}{l}\text { Gaillard, } \\
2014\end{array}$ & EDPS $>12$ & $\begin{array}{l}6-8 \\
\text { weeks }\end{array}$ & 264 & $44(16.7 \%)$ & 44 & $6(13.6 \%)$ & No \\
\hline $\begin{array}{l}\text { Goker, } \\
2012\end{array}$ & EDPS $>13$ & 6 weeks & 318 & $\begin{array}{l}100 \\
(31.4 \%)\end{array}$ & 106 & 37 (34.9\%) & No \\
\hline $\begin{array}{l}\text { Iwata, } \\
2015\end{array}$ & EDPS $>9$ & 6 months & 479 & $21.5 \%$ & 60 & $24(40 \%)$ & Yes \\
\hline $\begin{array}{l}\text { Patel, } \\
2005\end{array}$ & EDPS $>13$ & 8 weeks & 10,934 & N/A & 572 & $56(9.8 \%)$ & No \\
\hline Xie, 2011 & EDPS $>13$ & 2 weeks & 534 & $\begin{array}{l}103 \\
(19.3 \%)\end{array}$ & 149 & $24(16.1 \%)$ & $\begin{array}{l}\text { Yes: PPD higher in EICS } \\
\text { than EmCS }\end{array}$ \\
\hline \multicolumn{8}{|c|}{ Beck Depression Inventory } \\
\hline $\begin{array}{l}\text { Chen, } \\
2002\end{array}$ & BDI 9-10 & 6 weeks & 357 & N/A & N/A & N/A & No \\
\hline $\begin{array}{l}\text { Sarah, } \\
2017\end{array}$ & N/A & N/A & N/A & $33.4 \%$ & N/A & $13.8 \%$ of $33.4 \%$ & No mention \\
\hline $\begin{array}{l}\text { Ukpong, } \\
2006\end{array}$ & $\begin{array}{l}\mathrm{BDI}>9 \text { significant, } 10-18 \mathrm{mild} / \text { moderate, } \\
19-29 \text { moderate/severe, } 30-63 \text { extreme }\end{array}$ & $\begin{array}{l}6-8 \\
\text { weeks }\end{array}$ & 47 & $29.8 \%$ & 40 & N/A & No \\
\hline
\end{tabular}




\section{Mother-infant bonding}

Three studies examined the relationship between EmCS and mother-infant bonding [5, 35, 40] with conflicting results. Two studies utilised the Mother-to-Infant Bonding Scale $[5,40]$ and the third utilised the Parent-Child Early Relational Assessment Tool [35]. A recent, large scale cross-sectional study found EmCS appeared to have a negative association with mothers bonding and opening emotions with their baby. In contrast, a similar sized study reported no significant differences in mother-infant interactions at 4 or 12 months postpartum between MoD [35]. Similarly, a smaller scale cohort study found that type of CS did not appear to significantly affect mother-infant bonding in the first $72 \mathrm{~h}$ following delivery or at 12 weeks postpartum [40].

\section{Infant feeding}

Three studies examined the relationship between infant feeding and EmCS $[25,26,50]$. Study designs were prospective cohort, cross-sectional, and qualitative. The large scale prospective cohort study reported that women with EmCS were more likely to have an unsuccessful first breastfeeding attempt and were less likely to breastfed their baby within the first $24 \mathrm{~h}$ and upon leaving the hospital [50]. Furthermore, the study reported that women with EmCS had more breastfeeding difficulties (41\%), and used more hospital resources before and after leaving the hospital $(67,58 \%)$, in comparison to those with a VD $(29,40$, and $52 \%$, respectively) or a planned CS (33, 49, and 41\%, respectively). Additionally, a similar sized cross-sectional study reported that breastfeeding duration varied substantially with MoD [25]. In the same study, median breastfeeding duration was 45.2 weeks among women who had a spontaneous VD, 38.7 weeks among planned CS, 25.8 weeks among induced VD and 21.5 weeks among women with EmCS [25]. In the qualitative study women frequently stated that their decision to breastfeed was driven by their desire to make up for the traumatic way their baby was delivered, including, by EmCS [26]. In this study a women with EmCS stated, "breastfeeding became almost an act of vindication. I had to make up for failing to provide my daughter with a normal birth, so I sure wasn't going to fail again" [26].

\section{Sexual function}

Three studies, conducted in Israel, Iran and Spain, examined the relationship between EmCS and sexual function postpartum $[57,69,78]$, with inconsistent findings. A prospective cohort study reported a significantly higher proportion of women at 6 months postpartum being less satisfied with their sexual relations after birth in the forceps group (34\%) relative to the EmCS group (15\%) [78]. In contrast, a larger prospective cohort study reported that women who had a VD or EmCS had statistically significantly lower Female Sexual Function Index (FSFI) scores on average relative to those with a planned CS [69]. These findings were contrary to that of a small scale cohort study that found no significant difference between average sexual function scores and various MoD postpartum [57], potentially due to a lack of power.

\section{Experiences}

A large number $(n=21)$ of identified studies examined women's experiences with EmCS. A variety of measures were used across studies including: Impact of Event Scale, Wijma Delivery Expectancy/Experience Questionnaire, and Questionnaire for Assessing Childbirth Experience (QACE). Studies examined varying aspects of women's experiences of EmCS including women's overall birth experiences, emotional experiences and experiences with care and staff.

The majority of quantitative research studies found that EmCS was more likely to result in a negative birth experience. For example, a recent large prospective cohort study in Sweden reported that birth experience was more likely to be negative among women with EmCS relative to VD [53]. Similar findings were reported in another recent but smaller cross-sectional study, where unexpected MoD including EmCS resulted in a higher likelihood of negative birth experiences [48] with this finding supported in numerous other studies [32, 54, 83, 89]. Contrary to this finding, two prospective cohort studies reported that MoD had no direct influence on women's experience of childbirth $[38,74]$. Interestingly, in one of these studies no women in the EmCS subgroup attained a score which indicated a negative birth experience; rather $89 \%$ of these women described the birth experience as 'good/very good' [74]. Furthermore, the majority of women in this study with EmCS also evaluated their feelings of control during labour and the opportunities they had to make informed choices/decisions as 'good/very good' [74]. Interestingly, a large prospective study found that women who had a planned CS scored significantly lower in terms of negative birth perception than those who had an EmCS or a VD [30].

Twelve studies utilised a qualitative design to examine women's experiences of an EmCS [9, 31, 39, 44, 47, 49, $64,66,68,72,77,79]$. In all of these studies, women described a wide variety of emotions as salient to their EmCS experience however, a number of dominating negative experiences were consistent across all studies including: loss of perceived control and feelings of helplessness [9, 31, 39, 47, 49]; fear (own or/and for baby) [9, $31,64,66,68,77]$; and disappointment [9, 66, 77]. In a study conducted by Shorten [72] one participant reported "after an emergency caesarean I felt I had failed, I felt cheated of the childbirth experience I had wanted". 


\section{Experiences with maternity care and staff}

A large prospective cohort study reported that women who had an unplanned CS were more likely to indicate that they had received "less than good" midwifery care during childbirth [90]. It was suggested that as women who have an EmCS often have their care transferred to other care providers during childbirth, it is possible that the discontinuity of care between the providers may influence women's experiences with staff [90].

\section{Satisfaction}

Four studies examined women's satisfaction after EmCS $[28,37,46,70]$ with all reporting that women with EmCS were more likely to appraise their deliveries less favourably than those with other MoDs. In a large prospective cohort study conducted in both the Netherlands and England, EmCS appeared to be a contributing factor to a negative appraisal of birth [28].

\section{Self esteem}

Three studies examined women's self-esteem and EmCS $[32,55,56]$ with all studies reporting consistent findings. A cross sectional study reported that $\mathrm{MoD}$ influenced women's mood at one-month postpartum, with an item reading 'I am proud of myself', representing self-esteem, being more likely to have negative results for women with EmCS [32]. In two smaller Nigerian studies, women were more likely to report feelings of emotional vulnerability after delivery including feelings of failure, regret, and lower self-esteem $[55,56]$.

\section{Distress}

Three studies in Norway, Scotland and England examined distress in relation to EmCS $[23,58,63]$. In a very large prospective cohort study $(n=55,814)$ conducted over a 10 year period, no significant association between $\mathrm{MoD}$ and emotional distress postpartum was reported [23]. Further, a small cross-sectional study reported that women who gave birth assisted by instrumental delivery were more likely to report that their birth was distinctly more distressing than women in three other obstetric groups (VD, induced VD, EmCS) [58]. A mixed methods study reported that the fact that a CS was classified as an "emergency" frightened women, resulting in feelings of distress [63].

\section{Fear}

Two studies examined fear as an outcome of EmCS [75, 82]. A large prospective cohort study reported that EmCS was associated with increased fear of childbirth in subsequent pregnancies [75]. A similarly designed and sized study found that EmCS correlated with increased postpartum fear of childbirth a few days after the operation, however this decreased 1 month later [82].

\section{Other outcomes}

Childbirth burden and feelings of control were examined in two studies. A large cross-sectional study reported that women who experienced emergency surgical intervention (EmCS and vacuum extraction) were more likely to demonstrate higher childbirth burden scores than those with any other MoD [29]. A small cross-sectional study reported that women who had a spontaneous VD had a significantly higher sense of control during their labour and childbirth relative to those with an instrumental VD, a planned CS, or an EmCS [61].

\section{Discussion}

\section{Summary of findings}

A number of psychosocial outcomes were consistently and negatively reported to be associated by EmCS including post-traumatic stress, HRQoL, infant feeding, experiences, satisfaction and self-esteem. All studies examining post-traumatic stress consistently found that EmCS was a contributing factor for symptoms and PTSD after childbirth. Two studies exploring HRQoL reported consistent findings that women with EmCS had poorer physical functioning relative to other MoDs. Three studies examining infant-feeding reported that women with EmCS were more likely to have an unsuccessful first breastfeeding attempt, less likely to breastfed within the first $24 \mathrm{~h}$ and upon leaving the hospital, and to breastfeed for a shorter duration of time in comparison to other MoDs. These results are consistent with those reported by Ahluwalia [25] who noted that women with EmCS often experience; a difficult labour, stress, and delays in mother-infant interactions, each of which may reduce the likelihood or duration of breastfeeding.

Consistent findings were reported for satisfaction in that women with EmCS were more likely to appraise their deliveries less favourably than those with other MoDs. Studies examining self-esteem found women who had an EmCS were more likely to report feelings of emotional vulnerability after delivery including feelings of failure, regret, and lower self-esteem. Twenty one articles examined varying aspects of women's experiences of EmCS, which constituted the most commonly examined psychosocial outcome among included studies. In both quantitative and qualitative studies it was reported that women with EmCS were often at the highest risk of assessing their childbirth experience in a negative way and described a wide variety of negative emotions including: loss of perceived control and feelings of helplessness, fear (own or/and for baby), and disappointment.

Psychosocial outcomes including depression, motherinfant bonding, sexual function, fear, and distress were also identified and examined within in the literature. However, studies either reported mixed findings or no 
sufficient evidence of an association between these outcomes and EmCS.

\section{Limitations}

We recognise that potentially relevant articles could have been missed, written in languages other than English, or indexed in other databases other than those chosen and therefore may not have been identified. Studies identified in the review were conducted in 22 diverse countries and as such it must be acknowledged that cross-cultural differences are common and can greatly influence women's psychosocial outcomes of childbirth [91]. Postnatal access to healthcare; procedural differences; quality of available care; levels of social support; religious beliefs; poverty; societal attitudes regarding pregnancy, birth and motherhood; gender roles and attitudes regarding mental health problems are just a few of the known socio-cultural and environmental factors that may influence findings in the identified studies [92].

Of the included articles the strengths and meaningfulness of the findings differ substantially due to variations in study design, sampling procedures, and sample size. It has been previously identified that research examining the psychosocial outcomes of CS have generally suffered from numerous methodological limitations including; reliance on small sample sizes, use of measures of unknown reliability and validity and the lack of a comparison group or varying comparison groups [93]. Several of these limitations were present in the included studies. For example, as noted previously, one of the primary reasons for excluding articles was the failure to specify or differentiate between type of CS for women in a study. Furthermore, there was often no discussion within included studies about reasons and causes for EmCS and it is possible that some causes are more strongly associated with the psychosocial outcomes examined. Studies identified in the review reported on wide varying time frames for postpartum data collection, with collection ranging from hours after birth to years after birth as well ultilising different cut-points on the same measures for diagnosis. The timing of data collection is an important methodological consideration as there is considerable evidence that the impact of a women's birth experience changes over time [94]. As time passes, the positive affect from one's baby and satisfaction with being a mother has been shown in some cases to favourably influence a women's feeling about her labour experience [94].

As a result of the heterogeneous nature of these factors (exemplified in Table 3 for depression), meaningful pooled quantitative measures of study findings were unable to take place, even for subsets of studies. Overall, there appears a paucity of published evidence with consistent measures and adherence to guidelines for reporting (e.g. for cut-scores) which is crucial to rectify in future studies so that (gold standard) systematic literature reviews can meaningfully pool data in a quantitative manner.

\section{Strengths and implications}

To our knowledge, this study is the first to systematically review the available literature on women's psychosocial outcomes of EmCS. The review presents the findings of quantitative, qualitative and mixed methods studies from a vast array of countries and as a result identifies and examines a wide variety of psychosocial outcomes.

The review has highlighted the need for the further development of technologies and clinical practices to reduce the number of unnecessary EmCSs. Critically, it underscores the requirement for evidence based strategies to provide psychosocial support and information about EmCS in the context of routine antenatal and postnatal care. While high-level research currently exists in this area, for example in the form of routine debriefing to prevent psychological trauma after childbirth (103), it fails to show benefit. More broadly, while programs for postnatal psychosocial support have been promoted in many countries to improve maternal knowledge related to parenting, mental health, quality of life, and physical health, it has been concluded in a systematic review that the most effective strategies remain unclear [95].

\section{Conclusion}

The review has highlighted the diverse impact that EmCS can have on women. Numerous psychosocial outcomes that are negatively impacted by this $\mathrm{MoD}$ were identified including post-traumatic stress, healthrelated quality of life, experiences, infant-feeding, satisfaction, and self-esteem. In particular, there was strong consensus that EmCS contributes to symptoms and diagnosis of post-traumatic stress. This review has also highlighted the need for further investigation on this topic using robust methodology including the use of consistent, valid and reliable measures with consistent use of guidelines for appropriate cut scores, consistent comparison groups, adequately powered studies and differentiation between types of CS. Overall, enhanced knowledge and understanding in this area will provide an imperative step towards implementing effective strategies to improve women's health and well-being following EmCS. 


\section{Supplementary information}

Supplementary information accompanies this paper at https://doi.org/10. 1186/s12884-019-2687-7.

Additional file 1. Logic Grids.

\section{Abbreviations}

BDI: Beck's Depression Inventory; CS: Caesarean Section; EmCS: Emergency Caesarean Section; EPDS: Edinburgh Postnatal Depression Scale; HRQoL: Health Related Quality of Life; MMAT: Mixed Methods Appraisal Tool; MoD: Mode of Delivery; PPD: Postnatal depression; PROSPERO: Prospective register of systematic reviews; PRSIMA: Preferred Reporting Items for Systematic Reviews and Meta-analyses; PTSD: Post Traumatic Stress Disorder; QAR: Quality Assessment Rating; SF-36: Short-Form 36; VD: Vaginal delivery

\section{Acknowledgements}

We thank librarian Vikki Langton at the University of Adelaide library who provided support and knowledge in relation to performing the literature search. We would also like to thank all the authors and publishers of the original studies and the women who took part in all original research.

\section{Authors' contributions}

$M B, D T, A S$ have made substantial contributions to conception and design of the review. MB and NT conducted the literature search, initial screening of papers, full text assessment, and quality assessment of included studies. MB extracted data and characteristics of included studies. MB wrote initial manuscript and DT, AS, and CW provided intellectual content and extensive review of final manuscript. All authors read and approved the final manuscript.

\section{Funding}

The current study is funded by the NHMRC project grant 1129648. The funding body played no role in the collection, analysis, interpretation of data or in writing the manuscript.

\section{Availability of data and materials}

Not applicable.

\section{Ethics approval and consent to participate}

Ethics approval was not needed for this systematic literature review.

\section{Consent for publication}

Not applicable.

\section{Competing interests}

The authors declare that they have no competing interests.

\section{Author details}

${ }^{1}$ School of Psychology, University of Adelaide, Adelaide, South Australia, Australia. ${ }^{2}$ School of Public Health, University of Adelaide, Adelaide, South Australia, Australia. ${ }^{3}$ Maternal Fetal Medicine, Women's and Children's Hospital, Adelaide, South Australia, Australia.

Received: 19 May 2019 Accepted: 17 December 2019 Published online: 30 December 2019

\section{References}

1. Mazzoni A, Althabe F, Liu NH, Bonotti AM, Gibbons L, Sanchez AJ, et al. Women's preference for caesarean section: a systematic review and metaanalysis of observational studies. Bjog. 2011;118(4):391-9.

2. WHO Statement on Caesarean Section Rates. Geneva; 2015

3. Betrán AP, Ye J, Moller A-B, Zhang J, Gülmezoglu AM, Torloni MR. The increasing trend in caesarean section rates: global, regional and national estimates: 1990-2014. PLoS One. 2016;11(2):e0148343.

4. Boerma T, Ronsmans C, Melesse DY, Barros AJD, Barros FC, Juan L, et al. Global epidemiology of use of and disparities in caesarean sections. Lancet. 2018;392(10155):1341-8

5. Zanardo V, Soldera G, Volpe F, Giliberti L, Parotto M, Giustardi A, Straface G. Influence of elective and emergency cesarean delivery on mother emotions and bonding. Early Hum Dev. 2016;99:17-20.
6. le Riche H, Hall D. Non-elective caesarean section: how long do we take to deliver? J Trop Pediatr. 2005;51(2):78-81.

7. Organization WH. WHO statement on caesarean section rates. 2015.

8. Lobel MD, R. S. Psychosocial sequelae of cesarean delivery: review and analysis of their causes and implications. Soc Sci Med. 2007;64(11):2272-84.

9. Somera MJ, Feeley N, Ciofani L. Women's experience of an emergency caesarean birth. J Clin Nurs. 2010;19(19-20):2824-31.

10. Roux SL, van Rensburg E. South African mothers' perceptions and experiences of an unplanned caesarean section. J Psychol Afr. 2011;21(3):429-38.

11. Clement S. Psychological aspects of caesarean section. Best Pract Res Clin Obstet Gynaecol. 2001;15(1):109-26.

12. Haines HM, Rubertsson C, Pallant JF, Hildingsson I. The influence of women's fear, attitudes and beliefs of childbirth on mode and experience of birth. BMC Pregnancy Childbirth. 2012;12(1):55.

13. Nilver $H$, Begley $C$, Berg M. Measuring women's childbirth experiences: a systematic review for identification and analysis of validated instruments. BMC Pregnancy Childbirth. 2017;17(1):203.

14. Liberati A, Altman DG, Tetzlaff J, Mulrow C, Gøtzsche PC, loannidis JPA, et al. The PRISMA statement for reporting systematic reviews and meta-analyses of studies that evaluate health care interventions: explanation and elaboration. PLoS Med. 2009;6(7):e1000100.

15. Moher D, Liberati A, Tetzlaff J, Altman DG, The PG. Preferred reporting items for systematic reviews and meta-analyses: The PRISMA statement. PLoS Med. 2009;6(7):e1000097.

16. Koffel JB. Use of recommended search strategies in systematic reviews and the impact of librarian involvement: a cross-sectional survey of recent authors. PloS one. 2015;10(5):e0125931-e.

17. Long J, Cumming J. Psychosocial predictors. In: Gellman MD, Turner JR, editors. Encyclopedia of behavioral medicine. New York: Springer New York; 2013. p. 1584-5.

18. Aveyard $\mathrm{H}$. Doing a literature review in health and social care: A practical guide: McGraw-hill education; 2014

19. Timmins F, McCabe C. How to conduct an effective literature search. Nurs Stand. 2005;20(11):41-7.

20. Horsley T, Hyde C, Santesso N, Parkes J, Milne R, Stewart R. Teaching critical appraisal skills in healthcare settings. Cochrane Database Syst Rev. 2011;11: CD001270.

21. Pluye P, Robert E, Cargo M, Bartlett G, O'Cathain A, Griffiths F, Boardman F, Gagnon MP, Rousseau MC. A mixed methods appraisal tool for systematic mixed studies reviews. Proposal. 2011.

22. Boerleider AW, Wiegers TA, Manniën J, Francke AL, Devillé WL. Factors affecting the use of prenatal care by non-western women in industrialized western countries: a systematic review. BMC Pregnancy Childbirth. 2013; 13(1):81.

23. Adams SSE-G, M., Sandvik ÅR, Eskild A. Mode of delivery and postpartum emotional distress: A cohort study of 55814 women. BJOG. 2012;119(3): 298-305.

24. Adewuya AO, Ologun YA, Ibigbami OS. Post-traumatic stress disorder after childbirth in Nigerian women: prevalence and risk factors. BJOG. 2006; 113(3):284-8.

25. Ahluwalia IB, Li R, Morrow B. Breastfeeding practices: does method of delivery matter? Matern Child Health J. 2012;16(Suppl 2):231-7.

26. Beck CT, Watson S. Impact of birth trauma on breast-feeding: A tale of two pathways. Nurs Res. 2008;57(4):228-36.

27. Baas Cl, Wiegers TA, de Cock TP, Erwich JJ, Spelten ER, de Boer MR, et al. Client-related factors associated with a "less than good" experience of midwifery care during childbirth in the Netherlands. Birth. 2017:44(1):58-67.

28. Baston H, Marlies R, Green JM, Buitendijk S. Looking back on birth three years later: factors associated with a negative appraisal in England and in the Netherlands. J Reprod Infant Psychol. 2008;26(4):323-39.

29. Bergant AM, Moser R, Heim K, Ulmer H. Burden of childbirth: associations with obstetric and psychosocial factors. Arch Women's Mental Health. 1998; 1(2):77-81.

30. Bryanton J, Gagnon AJ, Johnston C, Hatem M. Predictors of women's perceptions of the childbirth experience. J Obstet Gynecol Neonatal Nurs. 2008:37(1):24-34.

31. Burcher P, Cheyney MJ, Li KN, Hushmendy S, Kiley KC. Cesarean birth regret and dissatisfaction: A qualitative approach. Birth. 2016;43(4):346-52.

32. Carquillat $P$, Boulvain M, Guittier MJ. How does delivery method influence factors that contribute to women's childbirth experiences? Midwifery. 2016; 43:21-8. 
33. Chen $\mathrm{CH}$, Wang SY. Psychosocial outcomes of vaginal and cesarean births in Taiwanese primiparas. Res Nurs Health. 2002;25(6):452-8.

34. Creedy DK, Shochet IM, Horsfall J. Childbirth and the development of acute trauma symptoms: incidence and contributing factors. Birth. 2000;27(2):104-11.

35. Durik AM, Hyde JS, Clark R. Sequelae of cesarean and vaginal deliveries: psychosocial outcomes for mothers and infants. Dev Psychol. 2000;36(2): 251-60.

36. Eckerdal P, Georgakis MK, Kollia N, Wikström AK, Högberg U, Skalkidou A Delineating the association between mode of delivery and postpartum depression symptoms: A longitudinal study. Acta Obstet Gynecol Scand. 2018.

37. Enabudoso El, A. R. Determinants of patient satisfaction after cesarean delivery at a university teaching hospital in Nigeria. Int J Gynaecol Obstet. 2011;114(3):251-4.

38. Fenaroli V, Saita E, Molgora S, Accordini M. Italian women's childbirth: a prospective longitudinal study of delivery predictors and subjective experience. J Reprod Infant Psychol. 2016;34(3):235-46.

39. Fenwick S, Holloway I, Alexander J. Achieving normality: The key to status passage to motherhood after a caesarean section. Midwifery. 2009;25(5): 554-63.

40. Forti-Buratti MA, Palanca-Maresca I, Fajardo-Simón L, Olza-Fernández I, Bravo-Ortiz MF, Marín-Gabriel MÁ. Differences in mother-to-infant bonding according to type of C-section: elective versus unplanned. Early Hum Dev. 2017;115:93-8

41. Furuta M, Sandall J, Cooper D, Bick D. Predictors of birth-related posttraumatic stress symptoms: secondary analysis of a cohort study. Arch Women's Ment Health. 2016;19(6):987-99.

42. Gamble J, Creedy D. Psychological trauma symptoms of operative birth. Br J Midwifery. 2005;13(4):218-24.

43. Gaillard A, Le Strat Y, Mandelbrot L, Keïta H, Dubertret C. Predictors of postpartum depression: prospective study of 264 women followed during pregnancy and postpartum. Psychiatry Res. 2014;215(2):341-6.

44. Gibbins JT, A. M. Women's expectations and experiences of childbirth. Midwifery. 2001;17(4):302-13.

45. Goker A, Yanikkerem E, Demet, M. M.; Dikayak, S.; Yildirim, Y.; Koyuncu, F. M. Postpartum depression: is mode of delivery a risk factor? ISRN Obstet Gynecol. 2012

46. Graham WJ, Hundley V, McCheyne AL, Hall MH, Gurney E, Milne J. An investigation of women's involvement in the decision to deliver by caesarean section. Br J Obstet Gynaecol. 1999;106(3):213-20.

47. Guittier MJ, Cedraschi C, Jamei N, Boulvain M, Guillemin F. Impact of mode of delivery on the birth experience in first-time mothers: a qualitative study. BMC Pregnancy Childbirth. 2014;14:254.

48. Handelzalts JE, Peyser AW, Krissi H, Levy S, Wiznitzer A, Peled Y. Indications for emergency intervention, mode of delivery, and the childbirth experience. PLoS ONE. 2017;12(1).

49. Herishanu-Gilutz S, Shahar G, Schattner E, Kofman O, Holcberg G. On becoming a first-time mother after an emergency caesarean section: A journey from alienation to symbolic adoption. J Health Psychol. 2009;14(7): 967-81.

50. Hobbs AJ, Mannion CA, McDonald SW, Brockway M, Tough SC. The impact of caesarean section on breastfeeding initiation, duration and difficulties in the first four months postpartum. BMC Pregnancy Childbirth. 2016;16:90.

51. Iwata H, Mori E, Tsuchiya M, Sakajo A, Maehara K, Ozawa H, Morita A, Maekawa T, Aoki K, Makaya M, Tamakoshi K. Predicting early post-partum depressive symptoms among older primiparous Japanese mothers. Jpn J Nurs Sci. 2015;12(4):297-308.

52. Jansen AJ, Duvekot JJ, Hop WC, Essink-Bot ML, Beckers EA, Karsdorp VH, Scherjon SA, Steegers EA, van Rhenen DJ. New insights into fatigue and health-related quality of life after delivery. Acta Obstet Gynecol Scand. 2007; 86(5):579-84.

53. Karlstrom A. Women's self-reported experience of unplanned caesarean section: results of a Swedish study. Midwifery. 2017;50:253-8.

54. Karlstrom A, Engström-Olofsson R, Norbergh KG, Sjoling M, Hildingsson I. Postoperative pain after cesarean birth affects breastfeeding and infant care. J Obstet Gynecol Neonatal Nurs. 2007;36(5):430-40.

55. Loto OM, Adewuya AO, Ajenifuja OK, Orji EO, Owolabi AT, Ogunniyi SO. The effect of caesarean section on self-esteem amongst primiparous women in South-Western Nigeria: a case-control study. J Matern Fetal Neonatal Med. 2009;22(9):765-9.

56. Loto OM, Adewuya AO, Ajenifuja OK, Orji EO, Ayandiran EO, Owolabi AT, Ade-Ojo IP. Cesarean section in relation to self-esteem and parenting among new mothers in southwestern Nigeria. Acta Obstet Gynecol Scand. 2010;89(1):35-8.

57. Lurie S, Aizenberg M, Sulema V, Boaz M, Kovo M, Golan A, Sadan O. Sexual function after childbirth by the mode of delivery: a prospective study. Arch Gynecol Obstet. 2013;288(4):785-92.

58. Maclean LI, McDermott MR, May CP. Method of delivery and subjective distress: Women's emotional responses to childbirth practices. J Reprod Infant Psychol. 2000;18(2):153-62.

59. Modarres M, Afrasiabi S, Rahnama P, Montazeri A. Prevalence and risk factors of childbirth-related post-traumatic stress symptoms. BMC Pregnancy Childbirth. 2012;12.

60. Noyman-Veksler G, Herishanu-Gilutz S, Kofman O, Holchberg G, Shahar G. Post-natal psychopathology and bonding with the infant among first-time mothers undergoing a caesarian section and vaginal delivery: sense of coherence and social support as moderators. Psychol Health. 2015;30(4): 441-55

61. O'Reilly A., Choby, D, Sejourne, Natalene; Callahan, Stacey. Feelings of control, unconditional self-acceptance and maternal self-esteem in women who had delivered by caesarean. J Reprod Infant Psychol 2014;32(4):355-365.

62. Patel R, Murphy DJ, Peters TJ. Operative delivery and postnatal depression: A cohort study. Br Med J. 2005;330(7496):879-81.

63. Porter M, Van Teijlingen E, Chi Ying Yip L, Bhattacharya S. Satisfaction with cesarean section: qualitative analysis of open-ended questions in a large postal survey. Birth. 2007;34(2):148-54.

64. Redshaw M, Hockley C. Institutional processes and individual responses: Women's experiences of care in relation to cesarean birth. Birth. 2010;37(2): 150-9.

65. Rowlands IJ, Redshaw M. Mode of birth and women's psychological and physical wellbeing in the postnatal period. BMC Pregnancy Childbirth. 2012;12.

66. Ryding EL, Wijma K, Wijma B. Experiences of emergency cesarean section: A phenomenological study of 53 women. Birth. 1998;25(4):246-51.

67. Ryding EL, Wijma K, Wijma B. Psychological impact of emergency cesarean section in comparison with elective cesarean section, instrumental and normal vaginal delivery. J Psychosom Obstet Gynaecol. 1998;19(3):135-44.

68. Ryding EL, Wijma K, Wijma B. Emergency cesarean section: 25 Women's experiences. J Reprod Infant Psychol. 2000;18(1):33-9.

69. Safarinejad MR, Kolahi AA, Hosseini L. The effect of the mode of delivery on the quality of life, sexual function, and sexual satisfaction in primiparous women and their husbands. J Sex Med. 2009;6(6):1645-67.

70. Saisto T, Salmela Aro K, Nurmi JE, Halmesmäki E. Psychosocial predictors of disappointment with delivery and puerperal depression: A longitudinal study. Acta Obstet Gynecol Scand. 2001;80(1):39-45.

71. Sarah SB, Forozan SP, Leila D. The relationship between model of delivery and postpartum depression. Ann Trop Med Public Health. 2017:10(4):874-7.

72. Shorten A, Shorten B, Kennedy HP. Complexities of choice after prior cesarean: a narrative analysis. Birth. 2014;41(2):178-84.

73. Soderquist J, Wijma K, Wijma B. Traumatic stress after childbirth: the role of obstetric variables. J Psychosom Obstet Gynaecol. 2002;23(1):31-9.

74. Spaich S, Welzel G, Berlit S, Temerinac D, Tuschy B, Sütterlin M, Kehl S. Mode of delivery and its influence on women's satisfaction with childbirth. Eur J Obstet Gynecol Reproduct Biol. 2013;170(2):401-6.

75. Storksen HT, Garthus-Niegel S, Vangen S, Eberhard-Gran M. The impact of previous birth experiences on maternal fear of childbirth. Acta Obstet Gynecol Scand. 2013;92(3):318-24.

76. Tham V, Christensson K, Ryding EL. Sense of coherence and symptoms of post-traumatic stress after emergency caesarean section. Acta Obstet Gynecol Scand. 2007;86(9):1090-6.

77. Tham V, Ryding EL, Christensson K. Experience of support among mothers with and without post-traumatic stress symptoms following emergency caesarean section. Sexual and Reproductive Healthcare. 2010;1(4):175-80.

78. Triviño-Juárez JM, Romero-Ayuso D, Nieto-Pereda B, Forjaz MJ, CriadoÁlvarez JJ, Arruti-Sevilla B, Avilés-Gamez B, Oliver-Barrecheguren C, MellizoDíaz S, Soto-Lucía C, Plá-Mestre R. Health related quality of life of women at the sixth week and sixth month postpartum by mode of birth. Women Birth. 2017;30(1):29-39.

79. Tully KP, Ball HL. Misrecognition of need: Women's experiences of and explanations for undergoing cesarean delivery. Soc Sci Med. 2013;85:103-11.

80. Ukpong DIO, A. T. Postpartum emotional distress: A controlled study of Nigerian women after caesarean childbirth. J Obstet Gynaecol. 2006;26(2):127-9.

81. Vossbeck-Elsebusch ANF, C: Ehring, T. Predictors of posttraumatic stress symptoms following childbirth. BMC Psychiatry. 2014;14(1). 
82. Wijma K, Ryding EL, Wijma B. Predicting psychological well-being after emergency caesarean section: A preliminary study. Journal of Reproductive and Infant Psychology. 2002;20(1):25-36.

83. Wiklund I, Edman G, Ryding EL, Andolf E. Expectation and experiences of childbirth in primiparae with caesarean section. BJOG: An International Journal of Obstetrics and Gynaecology. 2008;115(3):324-31.

84. Wiklund I, Edman G, Larsson C, Andolf E. First-time mothers and changes in personality in relation to mode of delivery. J Adv Nurs. 2009;65(8):1636-44.

85. Xie RH, Lei J, Wang S, Xie H, Walker M, Wen SW. Cesarean section and postpartum depression in a cohort of Chinese women with a high cesarean delivery rate. J Women's Health (Larchmt). 2011;20(12):1881-6.

86. Yang S-NS, Lih-Jong; Ping, Tao; Wang, Yu-Chun; Chien, Ching-Wen. The delivery mode and seasonal variation are associated with the development of postpartum depression. J Affect Disord 2011;132(1-2):158-164.

87. Yang SN, Shen $L$, Ping T, Wang YC, Chien CW. The delivery mode and seasonal variation are associated with the development of postpartum depression. J Affect Disord. 2011;132(1-2):158-64.

88. Adewuya AO, Ologun YA, Ibigbami OS. Post-traumatic stress disorder after childbirth in Nigerian women: prevalence and risk factors. BJOG. 2006; 113(3):284-8.

89. Wiklund I, Edman G, Larsson C, Andolf E. Personality and mode of delivery. Acta Obstet Gynecol Scand. 2006;85(10):1225-30.

90. Baas Cl, Wiegers TA, de Cock TP, Erwich JJHM, Spelten ER, de Boer MR, et al. Client-related factors associated with a "less than good" experience of midwifery care during childbirth in the Netherlands. Birth. 2017;44(1):58-67.

91. Halbreich U, Karkun S. Cross-cultural and social diversity of prevalence of postpartum depression and depressive symptoms. J Affect Disord. 2006; 91(2):97-111.

92. Dankner R, Goldberg RP, Fisch RZ, Crum RM. Cultural elements of postpartum depression. A study of 327 Jewish Jerusalem women. J Reprod Med. 2000:45(2):97-104.

93. DiMatteo MR, Morton SC, Lepper HS, Damush TM, Carney MF, Pearson M, et al. Cesarean childbirth and psychosocial outcomes: a meta-analysis. Health Psychol. 1996;15(4):303-14

94. Larkin P, Begley CM, Devane D. Women's experiences of labour and birth: an evolutionary concept analysis. Midwifery. 2009;25(2):e49-59.

95. Shaw E, Levitt C, Wong S, Kaczorowski J. The McMaster University postpartum research G. systematic review of the literature on postpartum care: effectiveness of postpartum support to improve maternal parenting, mental health, quality of life, and physical health. Birth. 2006;33(3):210-20.

\section{Publisher's Note}

Springer Nature remains neutral with regard to jurisdictional claims in published maps and institutional affiliations.

Ready to submit your research? Choose BMC and benefit from:

- fast, convenient online submission

- thorough peer review by experienced researchers in your field

- rapid publication on acceptance

- support for research data, including large and complex data types

- gold Open Access which fosters wider collaboration and increased citations

- maximum visibility for your research: over $100 \mathrm{M}$ website views per year

At $\mathrm{BMC}$, research is always in progress.

Learn more biomedcentral.com/submissions 